\title{
Mountain wave motions determined by the Esrange MST radar
}

\author{
A. Réchou, V. Barabash, P. Chilson, S. Kirkwood, T. Savitskaya, K. Stebel \\ Institutet för Rymdfysik, MRI-AFP, Box 812, S-981 28 Kiruna, Sweden
}

Received: 13 March 1998 / Revised: 10 February 1999 / Accepted: 15 February 1999

\begin{abstract}
A European campaign of ground-based radar, lidar and optical measurements was carried out during the winter of 1996/1997 (28 December-2 February) to study lee waves in the northern part of Scandinavia. The participants operated ozone lidars, backscatter lidars and MST radars at ALOMAR/Andoya and Esrange/Kiruna, and an ALIS imaging system in Kiruna. The Andoya site was generally windward of the Scandinavian mountains, the Kiruna site on the leeward side. The goal of the experiment was to examine the influence of lee waves on the formation of Polar Stratospheric Clouds (PSCs). This paper studies the radar data from MST-radar ESRAD located at Esrange $\left[68 .{ }^{\circ} \mathrm{N}, 21 .{ }^{\circ} \mathrm{E}\right]$, i.e. in the lee of the mountains. We present three cases where strong lee waves were observed: in one case they propagated upwards to the lower stratosphere and in the other two cases they were trapped or absorbed in the troposphere. We examine the local waves and the direction and strength of the local wind using the radar, the synoptic meteorological situation using weather maps (European Meteorological Bulletin) and the synoptic stratospheric temperatures using ECMWF data. We observed that waves propagate up to the stratosphere during frontal passages. When anticyclonic ridges are present, the propagation to the stratosphere is very weak. This is due to trapping of the waves at or below the tropopause. We also show that the radar data alone can be used to characterise the different weather conditions for the three cases studied (through the variation of the height of the tropopause). The synoptic stratospheric temperatures in the three cases were similar, and were above the expected threshold for PSC formation. Lidar and visual observation of PSCs and nacreous clouds, respectively, showed that these were present only in the case when the lee waves propagated up to the lower stratosphere.
\end{abstract}

Key words. Atmospheric composition and structure (aerosols and particles) - Electromagnetic (wave propagation) - Meteorology and atmospheric dynamics (mesoscale meteorology)

\section{Introduction}

When buoyancy provides a restoring force in the presence of stable stratification, disturbances called gravity waves are created in the atmosphere. These oscillations are common over mountain regions where they are named mountain lee waves and where they create an increase in the variance of vertical wind velocity. Ecklund et al. (1981, 1982), Nastrom et al. (1987), and Nastrom and Fritts (1992) have shown that the velocity variances in waves over mountainous regions were up to six times larger than those over oceans or plains. If the prevailing wind remains constant, the wave pattern can also remain fixed in relation to the obstacle, leading to the appearance of stationary lee waves.

Considering sources of gravity waves in the atmosphere, it is important to bear in mind the possibility of sources other than mountains. Orographic sources are generally the more important and also the best understood (Balsley and Carter, 1989; Bougeault et al., 1993; Leutbecher and Volkert, 1996; Carslaw et al., 1998a, b; Dörnbrack et al., 1998), however non orographic sources such as thunderstorms (Fovell et al., 1992), boundary layer convection (Clarke et al., 1986), fronts and jet systems (Griffiths and Reeder, 1996) have been recognised and their possible contribution in any particular case must also be considered.

Since the beginning of this century, particularly with the steadily increasing use of aircraft, atmospheric lee waves have become of more and more interest. The waves have been investigated using a number of different techniques, for example semi-Lagrangian techniques using instruments on board balloons, radio- 
sondes (Bretherton, 1969), gliders, and aircraft (Lilly et al., 1982; Nastrom et al., 1987), but also Eulerian techniques such as radar (Prichard et al., 1995), lidar (Blumen and Hart, 1988) and weather satellite images (Conover, 1964).

Although the semi-Lagrangian techniques, where the instruments move slowly relative to the air as it blows through the wave pattern, are able to measure the waves even if they are stationary, the Eulerian techniques, which are at a fixed point relative to the mountain chain, are best able for measuring lee waves when they vary due to a varying prevailing wind. In applying semi-Lagrangian techniques, the waves have often been considered to be time-independent. The assumption of a 'frozen' atmosphere, where the waves are stationary during several hours, is often adopted to analyse aircraft data (Lilly et al., 1982; Attie et al., 1991). More recently, with the introduction of Eulerian techniques it has become clear (Bougeault et al., 1993; Adams, 1996) that mountain lee waves sometimes propagate horizontally with non-zero phase speeds as measured from the ground. Lee waves can also propagate vertically in the atmosphere. In a uniform, isothermal atmosphere, they would propagate freely. However as the real atmosphere is neither isothermal nor uniform, wave propagation varies with position, and the waves may be absorbed or reflected at different heights in the troposphere or stratosphere.

Firstly, the waves can be absorbed at heights known as critical levels where the phase velocity of the waves matches the background wind in the direction of propagation. For stationary mountain lee waves, the phase velocity is zero and waves can be absorbed where the wind mean $U$ is nearly zero (if the wind direction is constant with height) or when the wind vector is orthogonal to the wave vector (if the wind rotates with increasing height). This behaviour has been observed in radar observations of lee waves by Worthington and Thomas (1996). On the other hand, for non-stationary mountain waves, Lott and Teitelbaum (1993) have shown that waves can propagate through regions where the background wind passes through zero, and any critical layers would occur at altitudes depending on the horizontal phase speed observed from the ground.

Secondly, the waves can be reflected where the Scorer parameter, which is a function of the atmospheric buoyancy, the wind speed and the vertical wind shear, become less than the horizontal wavenumber of the wave. In many cases, the Scorer parameter can be approximated simply by the ratio of buoyancy frequency to horizontal wind speed. Wave trapping can then occur if the cross-mountain wind increases strongly with height or if there is a low-level stable layer so that the buoyancy frequency decreases (stability decreases) with height (Holton, 1992). Ralph et al. (1992) have analysed how the incidence and the vertical structure of lee waves respond to the synoptic scale situation. They found that a transition from vertically propagating to trapped waves was related to the transit of a baroclinic system across the radar site. This brought both a reduction in stability in the upper troposphere, and a reduction in wind speeds in the same height interval. The first of these effects seemed to dominate in the Scorer parameter so that the waves were trapped.

In this paper, we analyse the generation and upward propagation of lee waves on three occasions as a function of the wind direction and velocity, but also as a function of the synoptic conditions. The radar data are used to examine both upward-propagating waves and waves which do not propagate upward. We use these case studies to take a first step towards classifying how the vertical propagation of the waves to the lower stratosphere is related to the winds and the synoptic conditions. Finally, we examine the implications of the waves in our case studies for the formation of Polar Stratospheric Clouds (PSCs), including nacreous clouds.

\section{Environmental conditions during the experiment}

\subsection{ESRAD MST radar system}

The radar used in this study is located at $67.56^{\circ} \mathrm{N}$, $21.04^{\circ} \mathrm{E}$ at $295 \mathrm{~m}$ above sea level, i.e. to the east of the Scandinavian mountains and above the Arctic circle. Salient parameters of the ESRAD radar are given in Table 1. In the measurements used here, the horizontal velocity was determined by the spaced-antenna technique and the vertical velocity from the Doppler shift. Measurements were obtained from 1 to $10-15 \mathrm{~km}$ altitude (depending on conditions) with a resolution of $300 \mathrm{~m}$ in height and $1 \mathrm{~min}$ in time. These measurements were complemented with a 1 min measurement every 10 min with $600 \mathrm{~m}$ height resolution (which gives stronger radar echo strengths).

MST radars such as ESRAD use the signals scattered from refractive index variations in the atmosphere. These fluctuations are caused by small-scale layering and by turbulence. They move passively with the displacement of atmospheric gases so that their movement can be used to determine the winds, and the

Table 1. ESRAD characteristics during winter 1996/1997

\begin{tabular}{ll}
\hline Location & $67.56^{\circ} \mathrm{N}, 21.04^{\circ} \mathrm{E}$ \\
Altitude & $295 \mathrm{~m}$ above sea level \\
Transmitter: & \\
Frequency & $52 \mathrm{MHz}$ \\
Duty cycle & $5 \%$ \\
Peak power & $72 \mathrm{~kW}(12 \times 6 \mathrm{~kW}$ modules $)$ \\
Pulse lengths & $1-50 \mu \mathrm{s}$ \\
Pulse repetition & $100 \mathrm{~Hz}-16 \mathrm{kHz}$ \\
Antenna: & $12 \times 12$ array \\
& $5-$ element Yagis \\
Spacing & $0.71 \lambda$ \\
Area & $44.4 \times 44.4 \mathrm{~m}$ \\
Receiver: & $6 \mathrm{separate}$ receivers \\
Sampling interval & $1-20 \mu \mathrm{s}$ \\
Filter & $250 \mathrm{kHz}-2 \mathrm{MHz}$ \\
Operation (ST-mode) & time resolution: 1 minute \\
& height resolution: $300 / 600 \mathrm{~m}$ \\
http://www.irf.se/mst/ & \\
EsrangeMST.html & \\
\hline
\end{tabular}


smaller scale velocity perturbations associated with the propagation of the waves. ESRAD operates continuously providing the three components of the wind vector in the troposphere, and lower stratosphere (and, in summer only, close to the mesospause).

A European campaign to study lee waves took place from 28 December 1996 to 2 February 1997, with ground-based instruments placedon both sides of the northern Scandinavian mountains. Several instruments took part: MST radars, backscatter lidars and ozone lidars located in both Andenes (69N, 16E) and Esrange $(68 \mathrm{~N}, 21 \mathrm{E})$, a high resolution CCD camera array (auroral large imaging system, ALIS) and other cameras located in and near Kiruna. The aim of the campaign was to study the importance of lee waves for the formation of polar stratospheric clouds, in particular to search for the generation, destruction or modification of PSCs as the air parcels crossed the mountain ridge and to study the dependence of lee-wave-modified PSCs on wind conditions (Fricke et al., 1998; Müller et al., 1998; Réchou et al., 1998; Serwazi et al., 1998).

\subsection{Topography around Kiruna}

The topography around Kiruna is illustrated in Fig. 1. As can be seen, the radar is located to the east of the Scandinavian mountains. These mountains lie in a long band running SSW-NNE along the border between Sweden and Norway. The highest mountains are located to the NW, SW and $\mathrm{W}$ of the radar, with the highest mountain in the area, Kebnekaise $(211.1 \mathrm{~m})$ located at $120 \mathrm{~km} \mathrm{~W}$ of the radar. This part of the mountain range is rather wide, about $100 \mathrm{~km}$ wide. To the NE of the radar, the mountains are lower, rather smooth and extend over a broad area. To the $\mathrm{E}$ of the radar, the area is rather smooth and is even more smooth to the SE, which is also below the level of ESRAD.

\section{Observation of lee waves}

\subsection{Mesoscale observation}

During January 1997, strong wave activity occurred over Kiruna on several occasions. We present in this paper three cases of wave activity. Figures $2(a, b)$, $3(a, b), 4(a, b)$ show the observations of radar echo strengths and the vertical velocity fluctuations from $1 \mathrm{~km}$ to $15 \mathrm{~km}$ altitudes for the 10, 24 and 26 January 1997, respectively. For all the cases the radar echo strength is shown as signal-to-noise ratio (SNR) between -20 to $30 \mathrm{~dB}$ and the fluctuation of vertical velocity between -1 to $1 \mathrm{~m} / \mathrm{s}$. Figure 5 shows the temperature and the potential temperature profiles from radiosondes - for 26 January 1997 from Bodo(d), for 24 January from Lulea (c) and for 10 January from Esrange (b). The humidity profile from Esrange (a) is also shown for 10 January. Bodo and Lulea are the nearest standard stations to the radar and lie $250 \mathrm{~km}$ to the WSW and $270 \mathrm{~km}$ to the SSE, respectively.

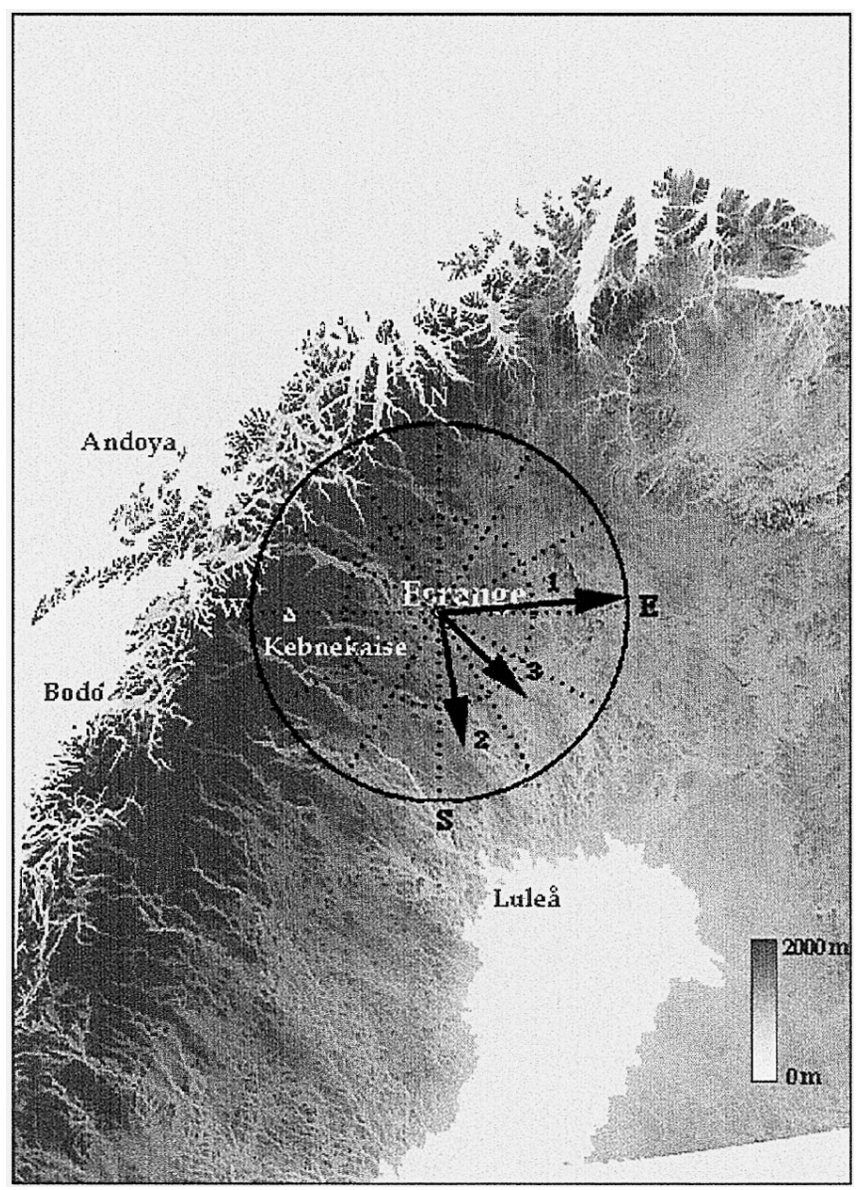

Fig. 1. Topography around Kiruna (copyright USGS, SSC Satellitbild) and ESRAD wind observations for the 10th (Day 1), 24th (Day 2) and 26th (Day 3) of January. The arrows represent the wind directions and wind speeds observed during these days

These different Figs. 2-4 and 5(a-d), show clearly that the atmosphere on 10 January (Figs. 2 and $5 \mathrm{a}-\mathrm{b}$ ) was very different to that on 24 and 26 January(Figs. 3, $5 \mathrm{c}, 4$ and $5 \mathrm{~d}$ ). The 10 th is characterised by a radar SNR $>0 \mathrm{~dB}$ at nearly all heights up to $9 \mathrm{~km}$ showing that the refractive index variations (due to turbulence in both dry and humid air) needed to provide a radar signal are present everywhere up to this height. Between 3 to $5 \mathrm{~km}$, however, the radar signal is relatively weak, which is correlated with a large decrease of the humidity at this level. As the humidity increases again higher up, the radar signals also increase again. Above $10 \mathrm{~km}$, the humidity becomes very small leading again to low signal levels.

On the 24th and the 26th, we see a more complex distribution of radar SNR. During these days, the SNR is positive up to $3.5 \mathrm{~km}$, falls to $<0$ between 6 and $11 \mathrm{~km}$ (presumably due to little humidity or low turbulence), and increases again in the upper most part of the troposphere. This latter sharp increase in SNR between $10-12 \mathrm{~km}$ is characteristic of the tropopause seen in radar data (Gage and Green, 1979) and seems to be due to fine scale layering at the sharp change in stability at the tropopause (sharp increase in the 

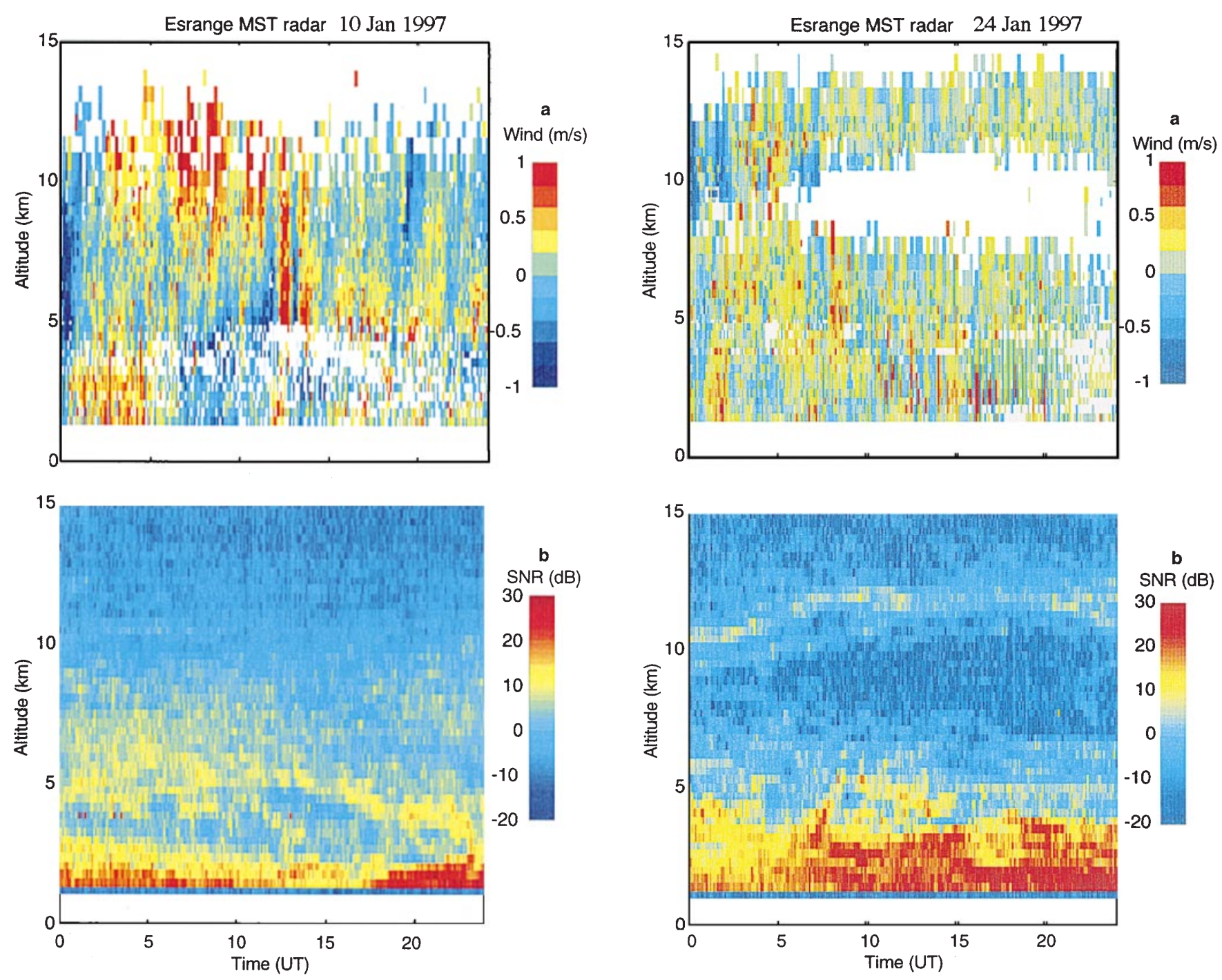

Fig. 2. ESRAD observations of vertical windspeed (a) and radar echo strength (b) for 10 January 1997

potential temperature gradient, seen clearly in the radiosonde data, Fig. 5(c-d)). In these two cases, we can see clearly the location of the tropopause, and can note that it is rather high. On the 24th, the tropopause rises from 10 to $12 \mathrm{~km}$ at around $3 \mathrm{UT}$, after which it remains nearly constant. On the 26th, the opposite occurs - at the beginning of the day it is around $12 \mathrm{~km}$, after which it falls to about $10 \mathrm{~km}$.

In contrast, on 10 January, a tropopause cannot be defined from the radar data. The absence of signal above $9 \mathrm{~km}$ corresponds to the beginning of the stratosphere, but there is clearly no sharp boundary between the troposphere and stratosphere. This is also seen in the radiosonde data (Fig. 5b) which shows that there is no sharp change in the temperature gradient at usual tropopause heights $(9-12 \mathrm{~km})$. Figure $5(\mathrm{a}-\mathrm{d})$ indicate a fairly close correlation between the profiles of radar SNR and humidity, and some relation to the profile of potential temperature which influences the stability and in turn the presence of turbulence.

Fig. 3. ESRAD observations of vertical wind speed (a) and radar echo strength (b) for 24 January 1997

The perturbations of the vertical velocity are also different in the three cases. On the 24th there is a rapid variation of vertical velocity with time (06-24 UT) suggesting that the waves propagate horizontally. On the 10th and the 26th vertical velocities vary more slowly indicating that the waves are quasi stationary.

On the 10th, there are continuous perturbations of the vertical velocity upto $\pm 1 \mathrm{~m} / \mathrm{s}$ at all heights up to the lower stratosphere (up to the limit of measurements at $12-13 \mathrm{~km}$ ). Between $05 \mathrm{UT}$ and 11 UT the perturbations even grow with height. This is to be expected since, if there is vertical propagation of the waves, the wave amplitude should increase with height due to the decrease of the atmospheric density. In contrast, on the 24th (after 5 UT) and more so on the 26th, there are large fluctuations of vertical velocity below $6 \mathrm{~km}$ altitude but these fluctuations seem to decay above there. On the 24th (after 5 UT) the fluctuations are generally rather smaller at the tropopause and, for example between 10-15 UT they seem to decay already between $6-7 \mathrm{~km}$. On the $26 \mathrm{th}$, the behaviour is similar, 

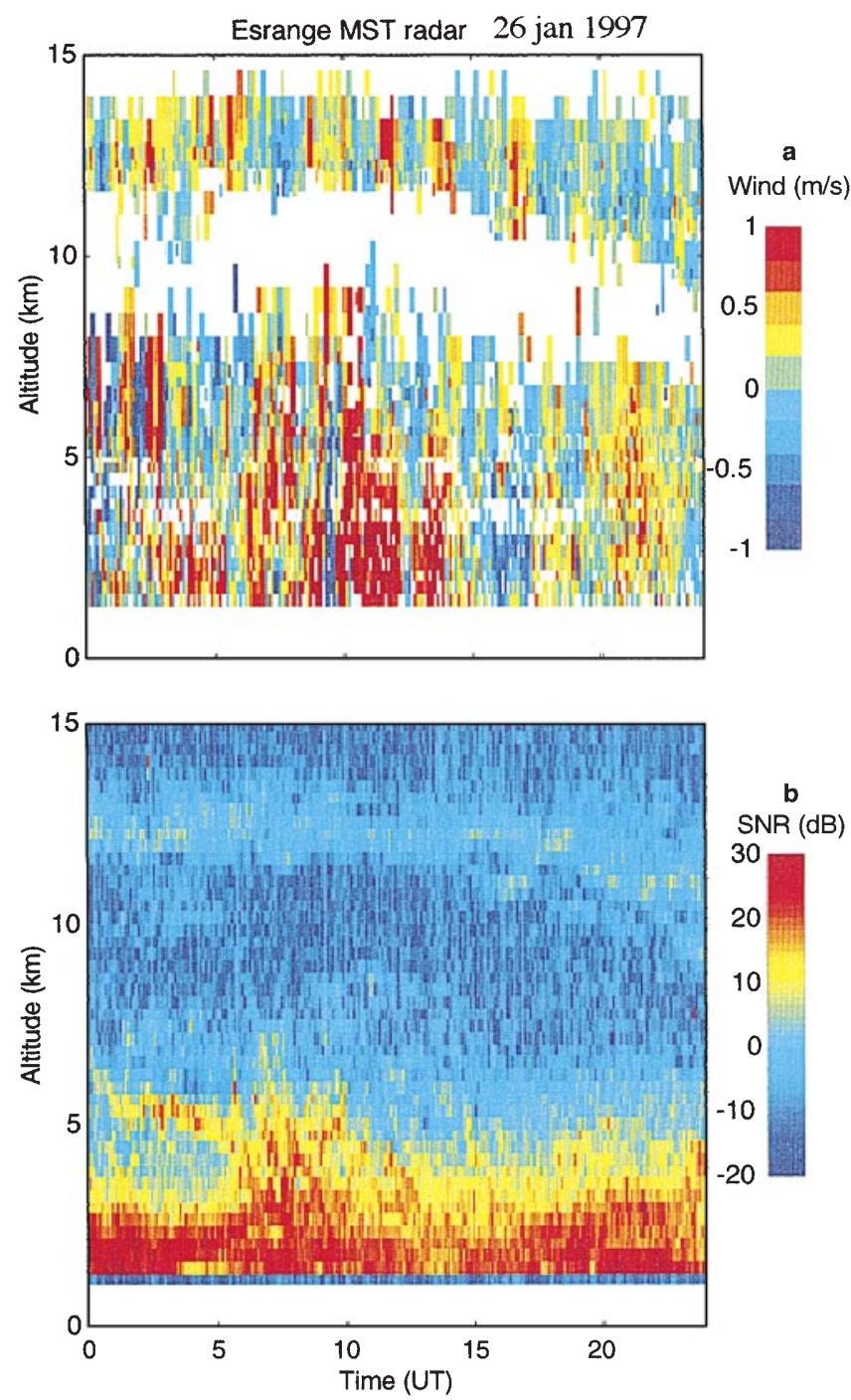

Fig. 4. ESRAD observations of vertical wind speed (a) and radar echo strength (b) for 26 January 1997

with rather less fluctuations at the tropopause than below $6 \mathrm{~km}$. Again there is a time period (11-14 UT) when the waves seem to decay already between 6-7 km. So it seems that the 24th and the 26th are characterised by waves which are trapped (reflected) or absorbed in the troposphere. The 10th, on the other hand, seems to be characterised by good vertical propagation of the waves.

\subsection{Synoptic situation}

The three cases also correspond to different synoptic weather conditions (Fig. 6). To asses this, we have studied the weather maps for the surface and for $500 \mathrm{hPa}$ (around $6 \mathrm{~km}$ )of the European Meteorological bulletin (published by Deutscher Wetterdienst). The 10th corresponds to the presence of a trough (Fig. 6ab), i.e. a long narrow area of low barometric pressure. The wind direction was from the NW throughout the day both at the ground and at $500 \mathrm{hPa}$. The presence of this lower pressure seems to disturb the tropopause, so that it cannot be distinguished in the radar data or in the radiosonde data, and also seems to increase the turbulence at the lower levels.

On the 24th, the first 3-5 h correspond to the last part of the passage of a warm front: the height of the tropopause increased and the front was followed by an anticyclone (with a high tropopause). At the beginning of the day, the wind was from NNW (at the ground and at $500 \mathrm{hPa}$ ), later from N-NNE.

The 26th, with winds from W (at the ground and at $500 \mathrm{hPa}$ ), corresponds to a region before the passage of a cold front. The tropopause was high at the start of the day (high pressure at $500 \mathrm{hPa}$ seen in the South of Scandinavia), but decreased towards the end of the day (with the start of the passage of the cold front). This is in agreement with Larsen and Rottger (1982) who found that frontogenesis is accompanied by a thermally-direct cross-front circulation with subsidence in the cold air and ascent in the warm air.

\section{Interpretation}

\subsection{Ground level effects}

The three cases analysed correspond to similar wind strengths but different wind directions. Figure 7 shows the variance of the vertical winds [as defined in Eq. 1] as a function of horizontal wind (polar co-ordinate). Each point represents a one-hour average between $1.3-3.2 \mathrm{~km}$ heights. Different symbols differentiate the three days analysed. We have adopted the definition of Ecklund et al. (1982) in using the variance of the vertical velocity as an indicator of gravity wave activity.

Eq. 1:

$\operatorname{Var}(W)=\left[\frac{\sum_{\mathrm{i}=1}^{n}\left(W^{\prime 2}-W^{* 2}\right)}{n}\right]$

where $W^{*}$ is the mean of the vertical velocity during $1 \mathrm{~h}$. $n$ : is the number of data points during $1 \mathrm{~h}$.

The 10th is characterised by NNW winds at speeds up to $25 \mathrm{~m} / \mathrm{s}$. In this case the biggest variance of vertical velocity is associated with winds less than $20 \mathrm{~m} / \mathrm{s}$. For the 24th, there is less variance of vertical velocity, and the wind is equally strong but more from the N, NNE. In contrast, on the 26th, which is associated with winds from the $\mathrm{W}$, again reaching about $25 \mathrm{~m} / \mathrm{s}$, there is large variance of the vertical velocity. This is in agreement with Ralph et al. (1992) who found that the largest wave activity is associated with winds from the highest, local, isolated topography. For our location, the largest top is Kebnekaise, i.e. to the $\mathrm{W}$ of the radar. On the 10th and 24th, the winds cross mountains which are smoother, lower, and broader, so the variance of vertical velocity is less.

\subsection{Vertical propagation}

To see whether the waves generated in the lower troposphere propagate up to the stratosphere, we 

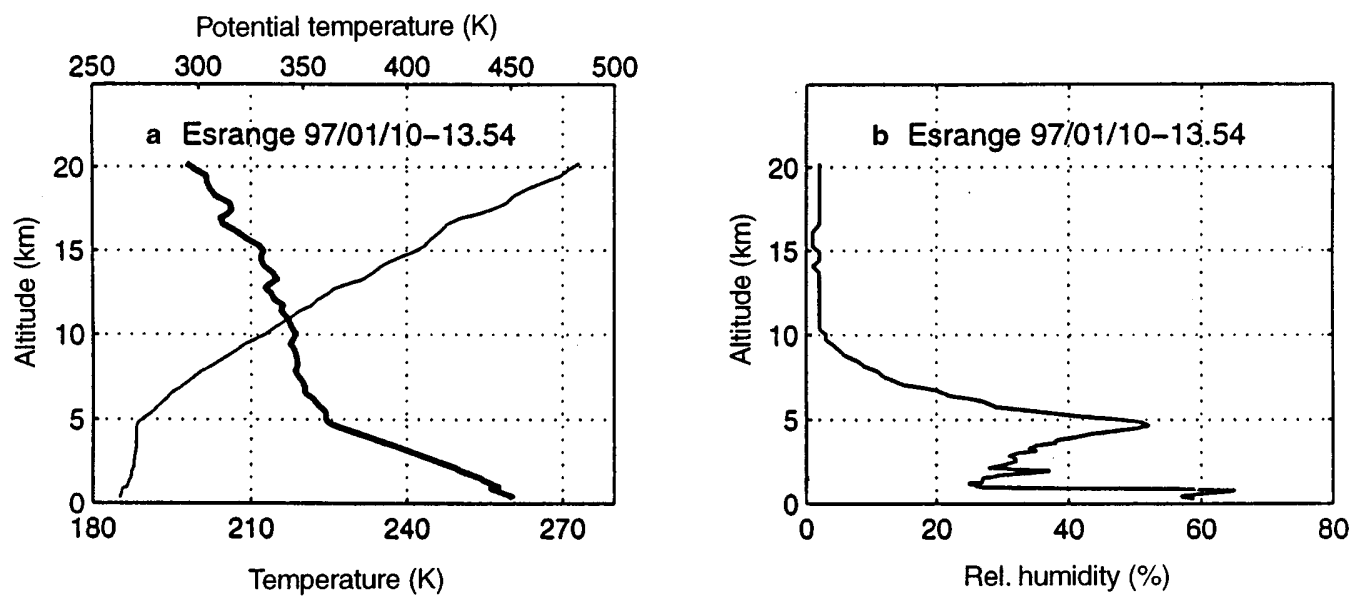

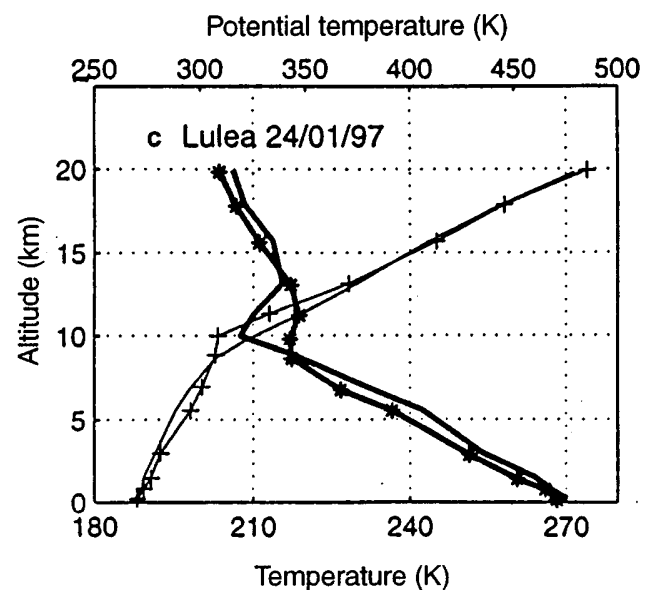

Fig. 5. Radiosonde data a from Esrange showing temperature (thick line) and potential temperature (thin line) and $\mathbf{b}$ humidity for 10 January, c from Lulea showing temperature (0 UT: thick line; 12 UT: -*) and potential temperature for 0 UT (thin line) and 12 UT $( \pm)$

examine the vertical winds up to the highest level available. Since the three cases are characterised by very different vertical structure in the wave perturbations, they must also be characterised by different conditions for the vertical propagation of waves. This can be studied with the help of Figs. 2-4, and $8 \mathrm{a}-\mathrm{c}$. In the latter, 1-h averages of the vertical velocity are shown. This allows us to remove small scale waves and minimise the effects of convection (Prichard et al., 1995). In parallel, we have plotted the ESRAD observations of the horizontal wind for each day in Fig. 9a-c.

In Fig. 2 we see that the 10th is characterised by a continuous perturbation of the vertical velocity up to at least $13 \mathrm{~km}$, i.e. the lower most stratosphere. Also in Fig. 8 we can see that there is good vertical propagation of the waves: the vertical velocity changes sign with height. If we look at the horizontal wind (Fig 6b-9a), we can see that it increases with height. At the upper levels the wind is strong and from the NW. There is a change of wind direction between 3 and $4 \mathrm{~km}$, which does not seem to affect the vertical propagation of the waves. Below, the wind is again from the NW and stronger than between $3-4 \mathrm{~km}$. The variation of the wind is perhaps a signature of the presence of the trough. Notable for this case is that, even if the winds in the upper part are strong, there is still upward propagation of the waves.

On the 24th, the perturbation is largest below $5 \mathrm{~km}$, weaker between $6-8 \mathrm{~km}$, cannot be observed in the part without radar signal $(8-11 \mathrm{~km})$ and very weak around the tropopause $(11-14 \mathrm{~km})$. Similarly on the 26th, there seems to be good propagation in the lower part, up to $6 \mathrm{~km}$ (until $16 \mathrm{UT}$ ), but in the upper part near the tropopause the perturbation of the vertical velocity is very weak: the waves seems to be trapped.

In order to explain whether the waves are trapped or propagate to the upper levels we must examine the conditions in more detail.

Static stability, which provides the restoring force for vertical oscillations, is the essential positive contribution to the vertical propagation of the waves. In fact, the greater the Brunt-Vaissala frequency $N^{2}$, the shorter the vertical wavelength and the more vertical propagation is favoured. So we have plotted in Figs. 10a, 11a, 12a, for the 10th, 24th and 26th respectively, the profile of the 
a 10 January 1997
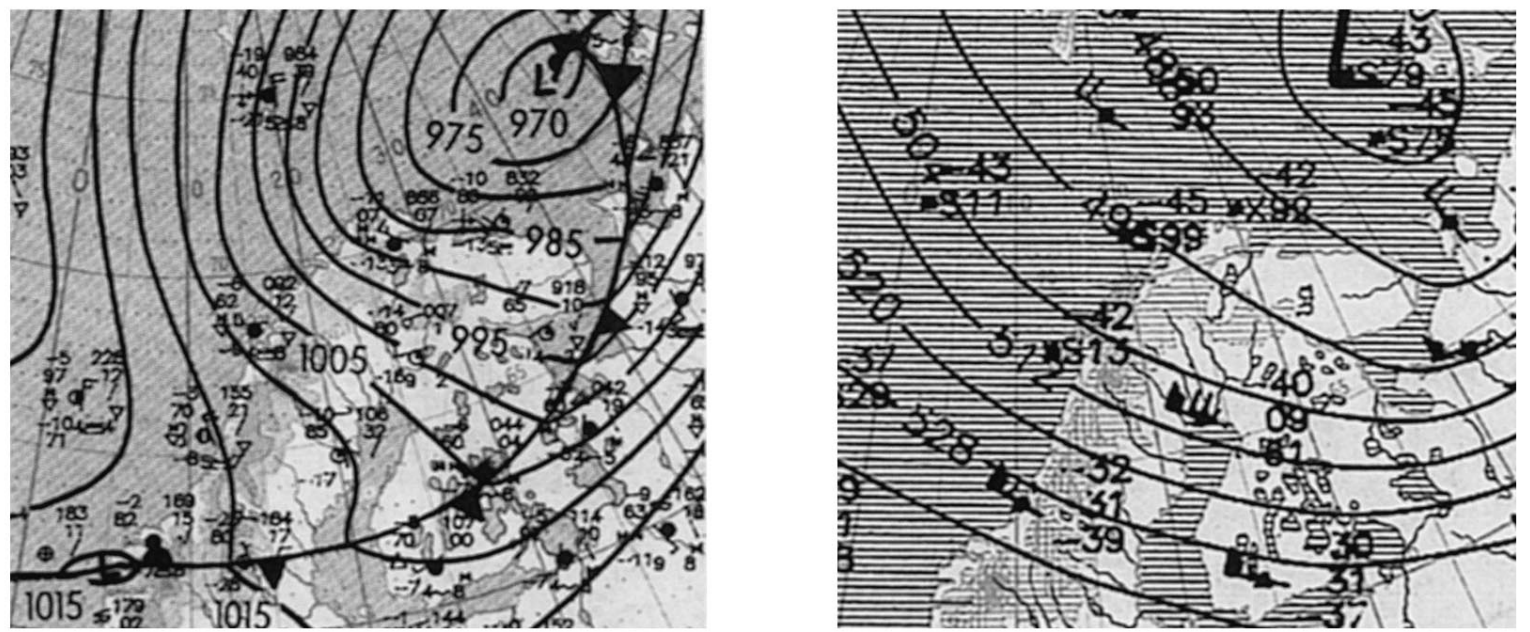

b 24 January 1997
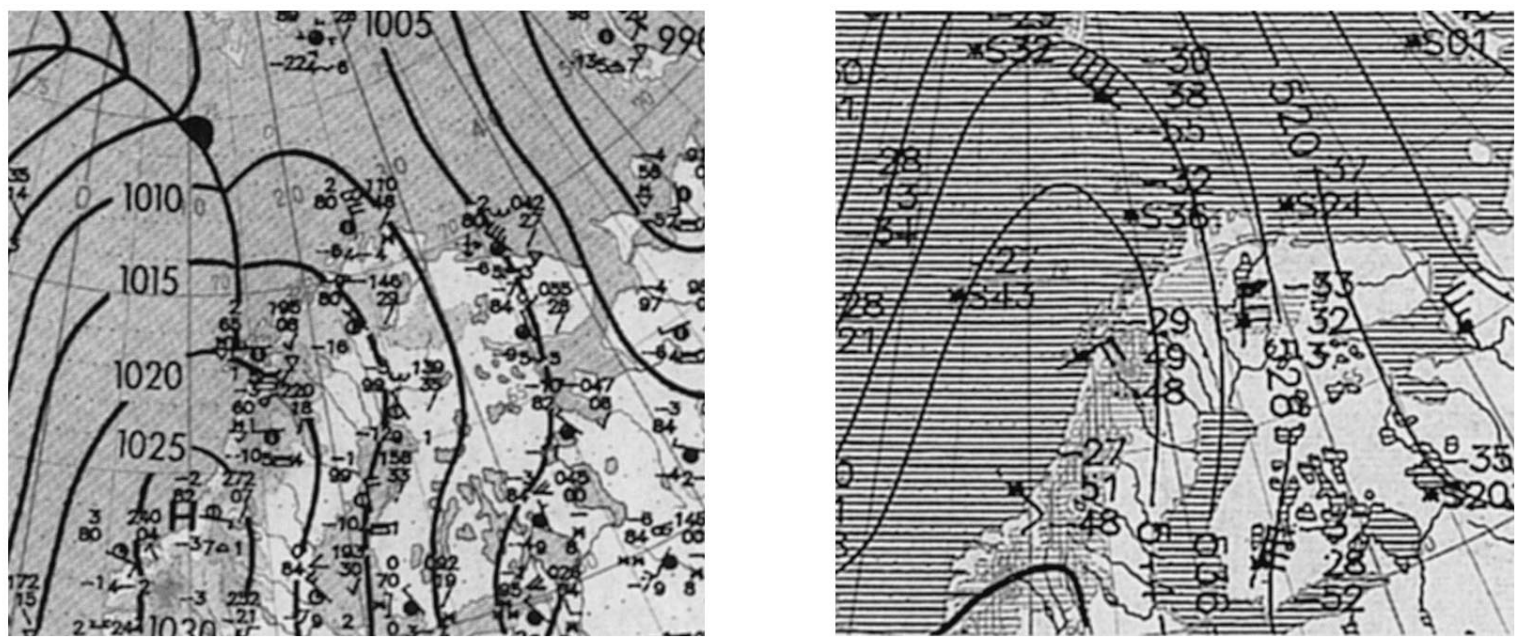

c 26 January 1997
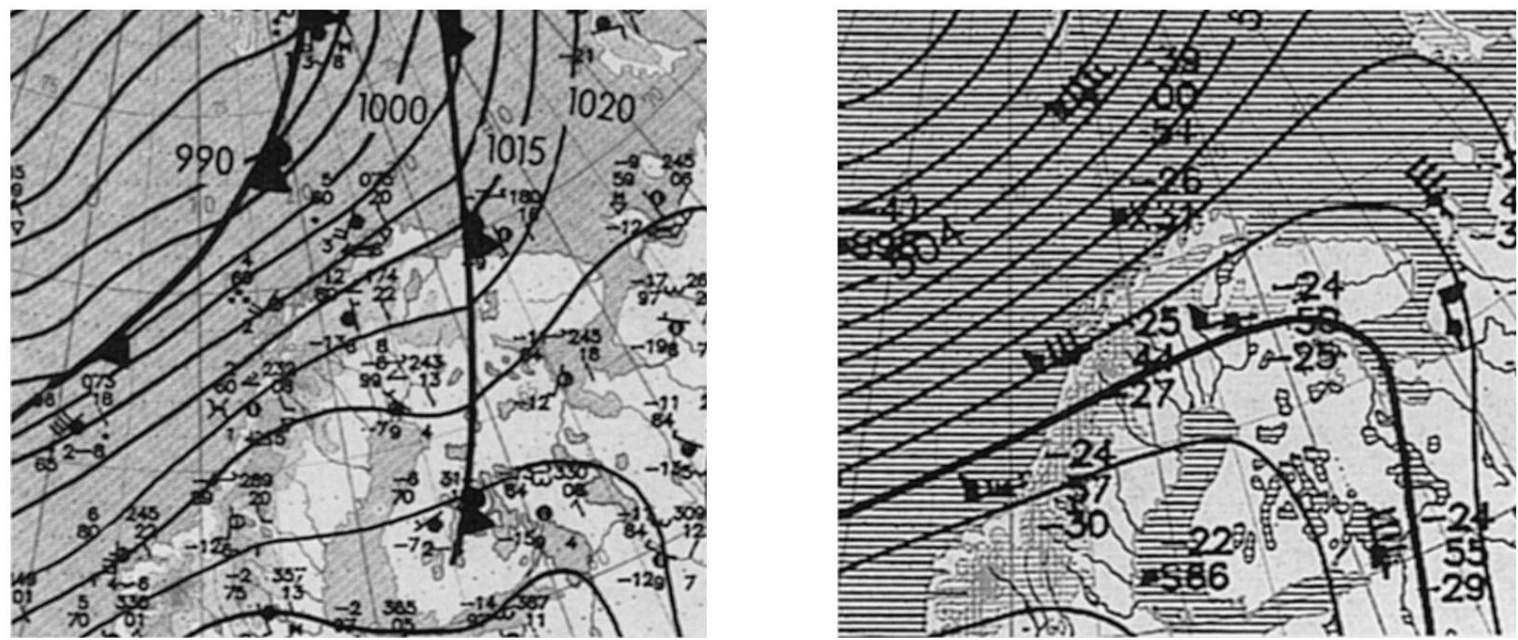

Fig. 6. Synoptic maps at surface (left) and at $500 \mathrm{hPa}($ right $)$ of wind and temperature fields in northern Scandinavia; a for 10 January b for 24 January $\mathbf{c}$ for 26 January. The maps are from the European Meteorological Bulletin and published by Deutscher Wetterdienst 


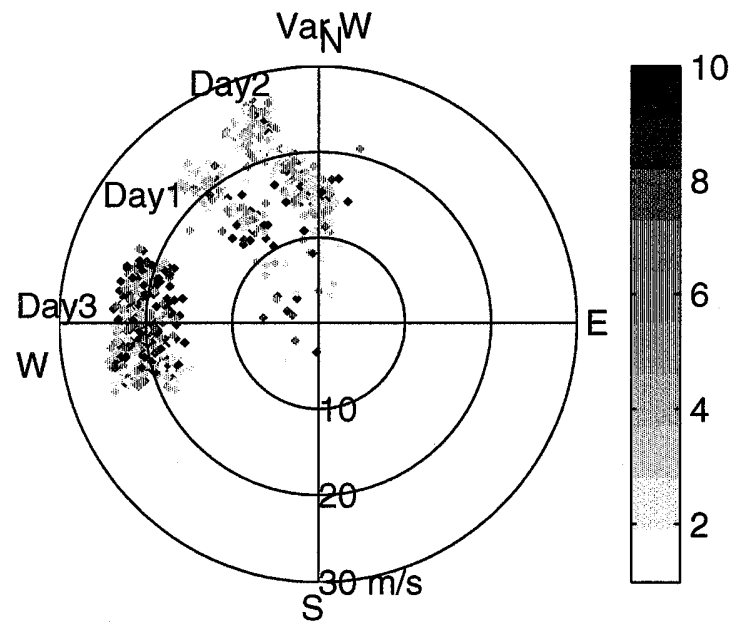

Fig. 7. Variance of vertical wind (gray scale) as a function of horizontal wind (polar co-ordinate). Each point represents the variance over one hour during 10 (Day 1), 24 (Day 2) and 26 (Day 3) January 1997
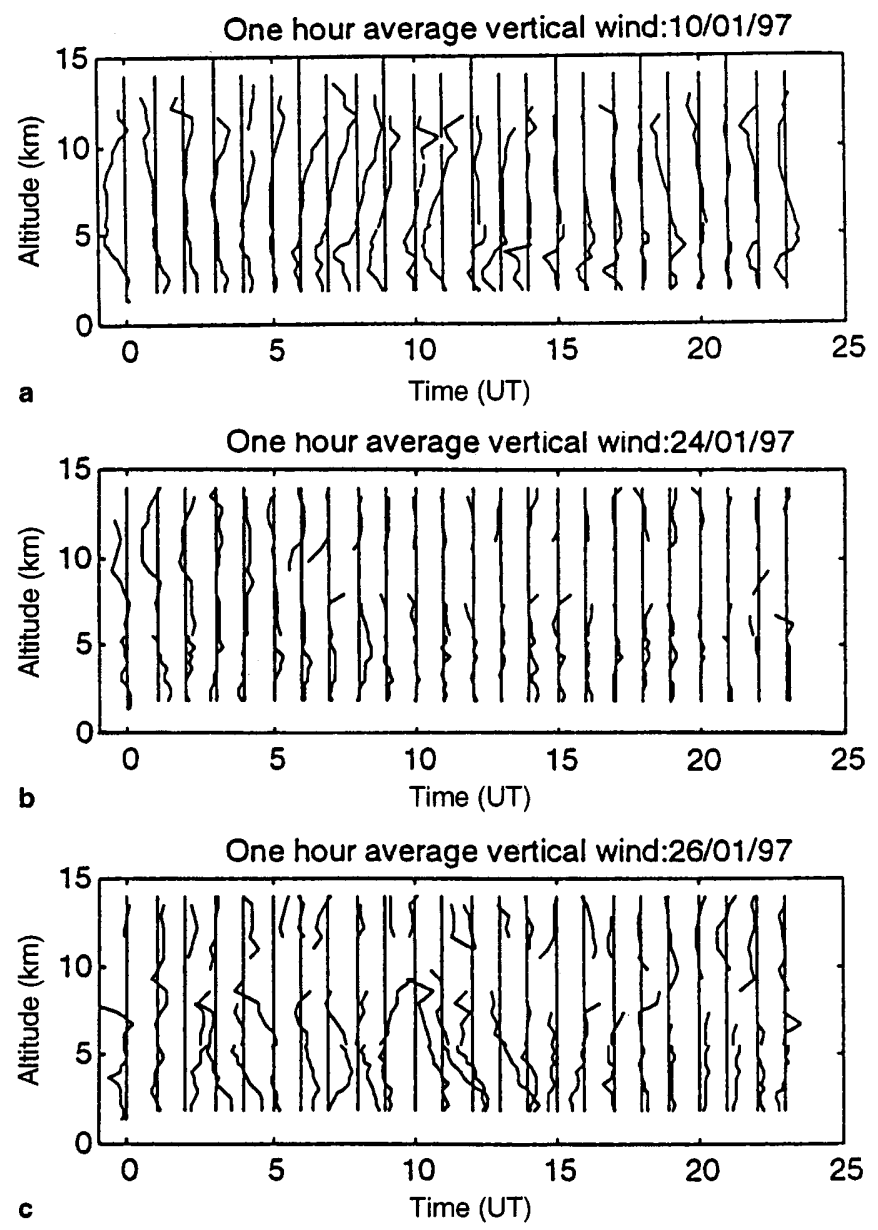

Fig. 8. Profiles of hourly vertical wind averages for 10 January 1997 (a), for 24 January 1997 (b) and for 26 January 1997 (c). The distance between the profiles corresponds to $1 \mathrm{~m} / \mathrm{s}$

Fig. 9. ESRAD observations of horizontal wind vectors for 10 January 1997 (a), for 24 January 1997 (b) and for 26 January 1997 (c)
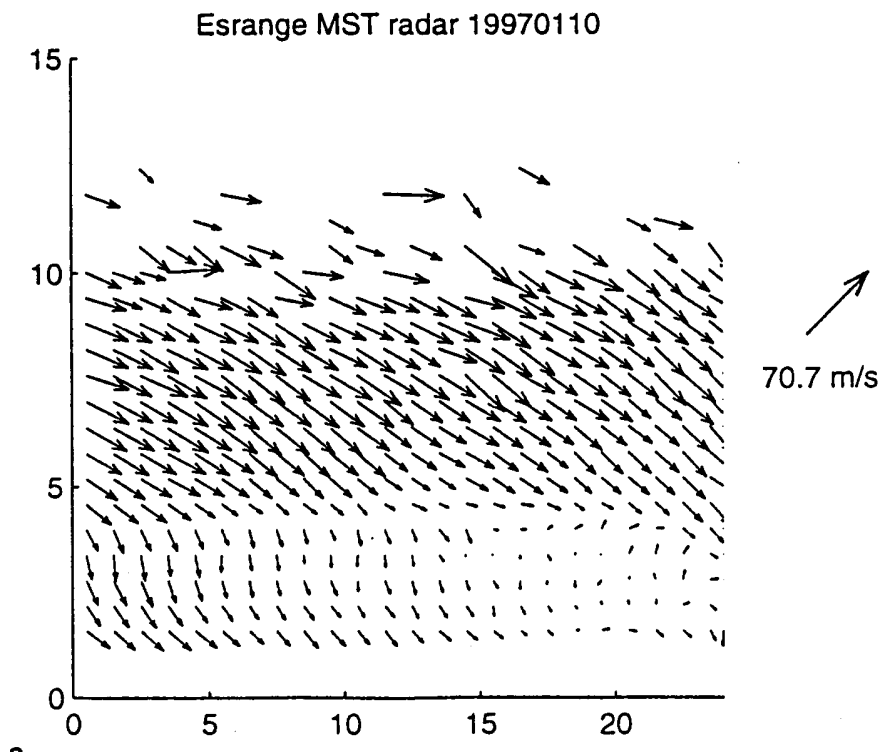

Esrange MST radar 19970124

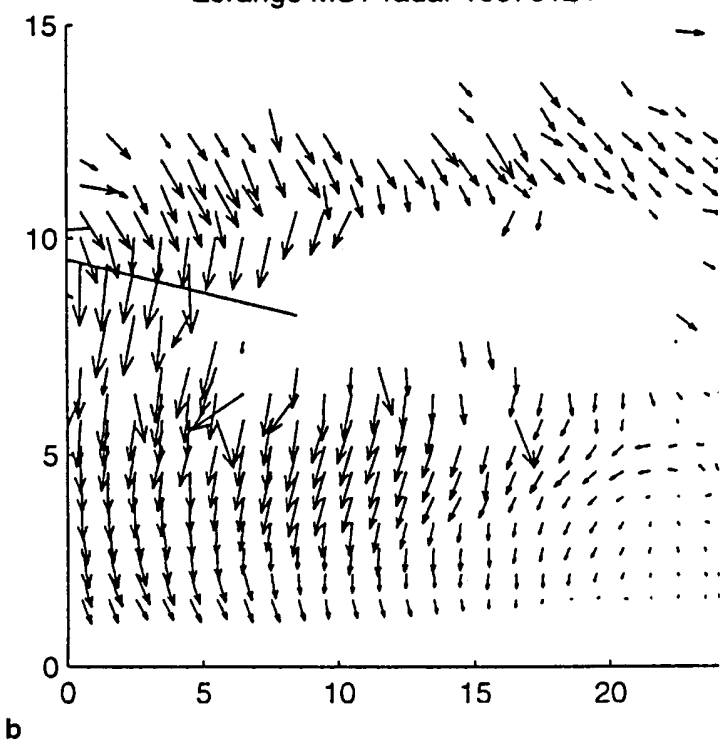

b

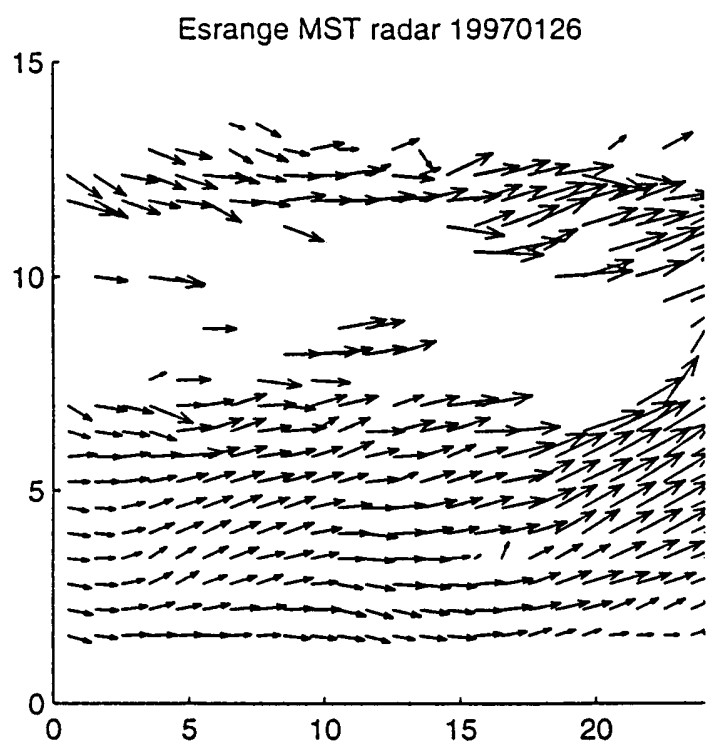

$70.7 \mathrm{~m} / \mathrm{s}$ 
10 January 1997
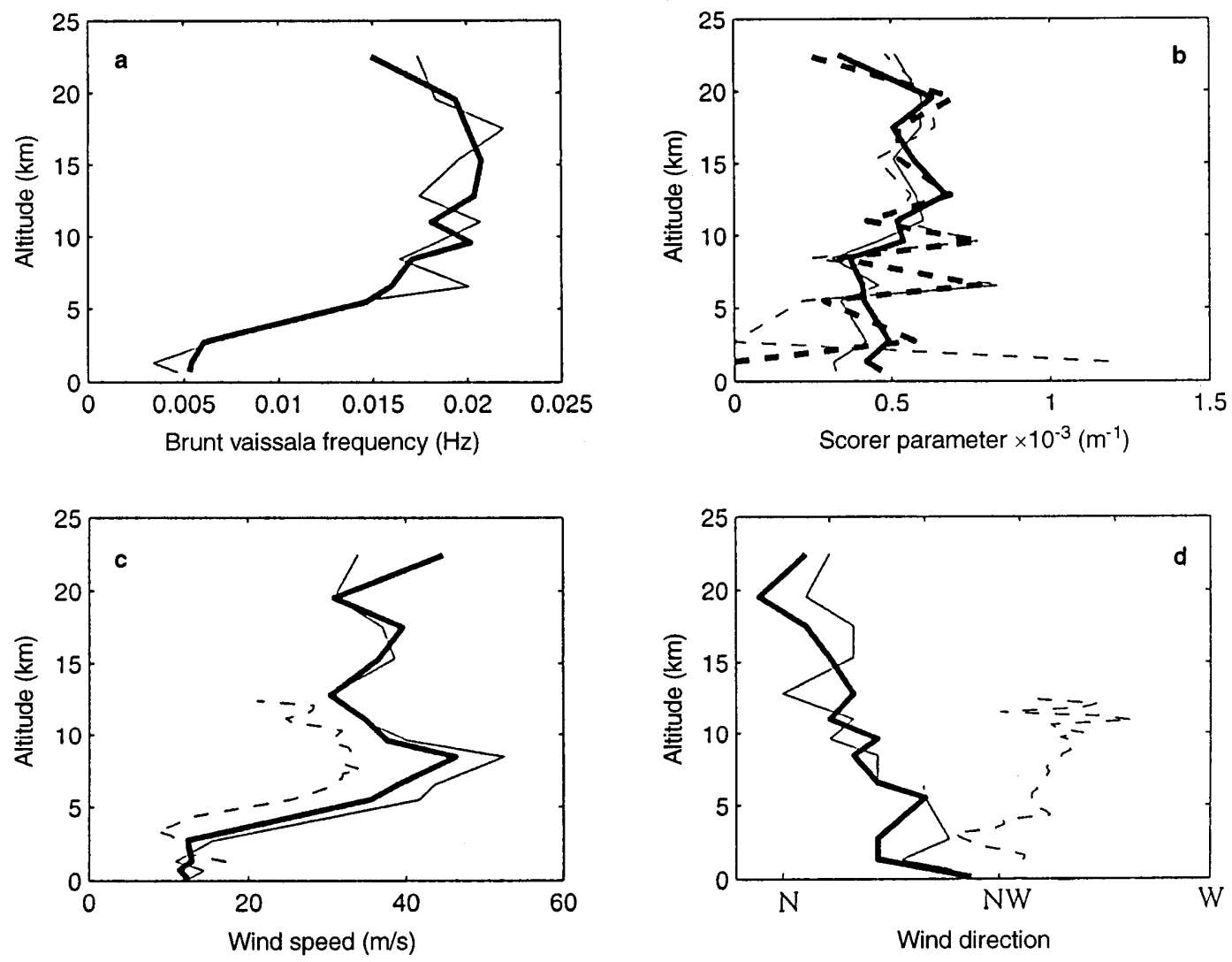

Fig. 10. Profiles for 10 January for 0 UT (thin line) and 12 UT (thick line) a Brunt Vaissala frequency from radiosonde from Bodo. b Scorer parameter from radiosonde from Bodo (solid line: simplified, dashed: full expression, see text). $\mathbf{c}$ Wind intensity from radiosonde from Bodo

(solid), ESRAD radar data (24-h average - dashed). d Wind direction from radiosonde from Bodo (solid line), ESRAD radar data (dashed line) Zero degrees is westerly, -90 northerly

Brunt Vaissala frequency using temperature data from the radiosondes launched from Bodo, i.e. $250 \mathrm{~km} \mathrm{SSW}$ of the radar site.

Eq. (2):

$N^{2}=g \frac{\mathrm{d} \ln \theta}{\mathrm{d} z}$

Another critical parameter for the vertical propagation of wave is the Scorer parameter. For the two dimensional case, the lee wave vertical structure equation reduces to the form:

Eq. (3):

$\frac{\mathrm{d}^{2} W}{\mathrm{~d} z^{2}}+\left(l^{2}-k_{x}^{2}\right) W=0$

where

Eq. (4):

$l^{2}=\frac{N^{2}}{U^{2}}-\frac{1}{U} \frac{\mathrm{d}^{2} U}{\mathrm{~d} z^{2}}$

and $l$ is known as the Scorer parameter. For vertical propagation of waves the condition $k s^{2}<l^{2}$ must be fullfilled, where $k s$ is the horizontal wave number of the gravity wave. The inverse of the Scorer parameter, $\lambda_{s}$, with some simplification, can be interpreted as the critical horizontal wavelength for propagation (setting

$2 \pi l^{-1}=\lambda_{s}$ gives $\lambda_{s}$ as the horizontal distance traversed by an air parcel during one period of its buoyancy oscillation). The profile of the Scorer parameter is the best indicator of the conditions for the vertical propagation of the waves, because it takes into account both the profile of the temperature (through the Brunt Vaissala frequency) and the profile of the background wind. A decrease of the Scorer parameter with height (corresponding to an increase of the critical horizontal wavelength) indicates that the waves are progressively coming closer to being trapped as the short horizontal wavelengths become less able to propagate vertically than the long horizontal wavelengths. For example, Scorer (1949), Corby and Sawyer (1958) found that a rapid decrease of $l$ with height in the lower troposphere sets up a wave-guide in which the waves amplitudes can become large and in which the large wave amplitudes can be effectively trapped.

The Scorer parameter is plotted in Figs. 10b, 11b, and $12 \mathrm{~b}$, for the 10th, 24th and 26th respectively, using the radiosonde data from Bodo, The profile of the scorer parameter is plotted both as defined above and simplified $(l=N / U)$, considering that the curvature of the profile of $U\left(\mathrm{~d}^{2} U / \mathrm{d}^{2} z / U\right)$ is negligible compared to $N^{2} / U^{2}$. The full expression is very 'noisy' because of the limited height resolution of the standard radiosonde data. 


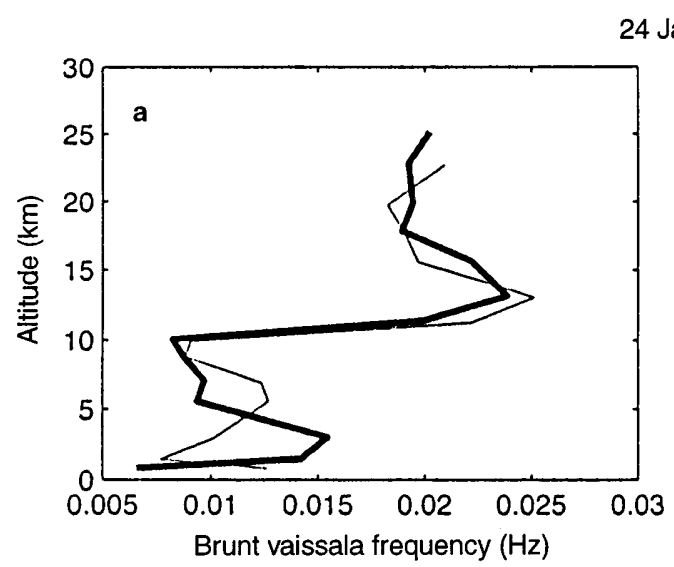

24 January 1997

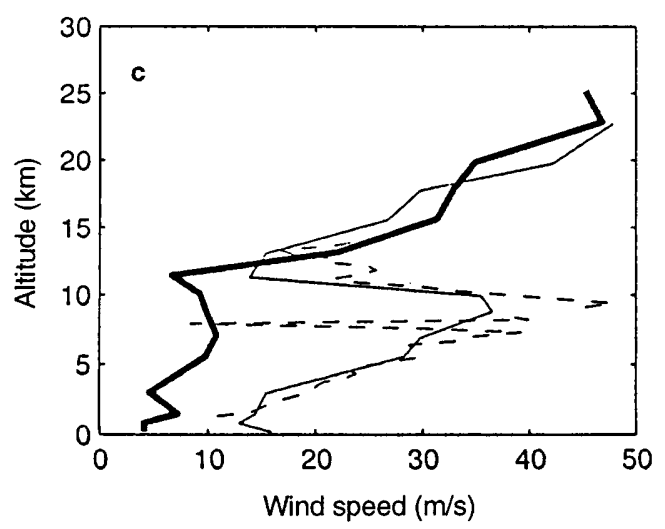

Fig. 11. Profiles for 24 January for 0 UT (thin line) and 12 UT (thick line) of a Brunt Vaissala frequency from radiosonde from Bodo. b Scorer parameter from radiosonde from Bodo (solid line: simplified, dashed: full expression, see text). c Wind Intensity from radiosonde

The vertical propagation is also controlled by the mean flow where it depends on the presence or the absence of critical layers: if the mean wind vanishes or if it's direction is perpendicular to the wave propagation, a critical layer will appear leading to absorption of wave activity. The speed and the direction of the mean wind are also plotted in Figs. 10, 11, and 12(c-d), from both radiosonde data (Bodo) and from the ESRAD radar data.

On the 10th (Fig. 10), the Brunt Vaissala frequency increases with height up to $6-10 \mathrm{~km}$. The (simplified) Scorer parameter, also increases slightly with height so there is no hindrence to vertical propagation in this parameter. The wind speed increases from $1 \mathrm{~km}$ to $9 \mathrm{~km}$, decreases above there but does not drop below $30 \mathrm{~ms}^{-1}$, and the direction varies little with height. So there is no critical level.

The 10th is characterised by the passage of a trough: the lower levels are disturbed (low stability), the tropopause not well defined and the Brunt-Vaissala frequency increases steadily with height. (In cases where the tropopause is well defined the Brunt-Vaissala frequency is lower in the upper troposphere and increases abruptly at the tropopause, see below). There is a constant increase of the horizontal wind with height and little change of direction which avoids critical levels, but could have led to wave trapping if not counteracted by the increase in Brunt-Vaissala frequency.

On the 24th (Fig. 11), at the start of the day (00 UT), the Scorer parameter decreases slightly with height up to $10 \mathrm{~km}$, where it increases sharply with the Brunt Vaissala frequency. Later (12 UT), following the profile of the Brunt Vaissala frequency, it first increases up to $3 \mathrm{~km}$, decreases up to $5 \mathrm{~km}$, remains low up to $10 \mathrm{~km}$ and then increases again. Given the 'noise' in the estimates of the Scorer parameter, it is difficult to be sure if the decrease between 3 and $10 \mathrm{~km}$ is real - if so, it could explain the disappearance of waves in the upper troposphere. The rapid decrease of the Scorer parameter above $12 \mathrm{~km}$ which is seen both at 0 UT and $12 \mathrm{UT}$, would certainly hinder propagation to even higher altitudes. Considering the wind speed and direction for the 24th, we see that the wind speed and direction change dramatically just above $10 \mathrm{~km}$, from NE at the lower levels, to NW above the tropopause (also seen clearly in Fig. 11). So it is also possible that upward propagation of lee waves is stopped by a critical level in this case.

The 24th is characterised by an anticyclonic ridge, the tropopause height increases during the day and it is well defined. In this example the propagation of the waves to the lower stratosphere may be controlled by the change 
26 January 1997
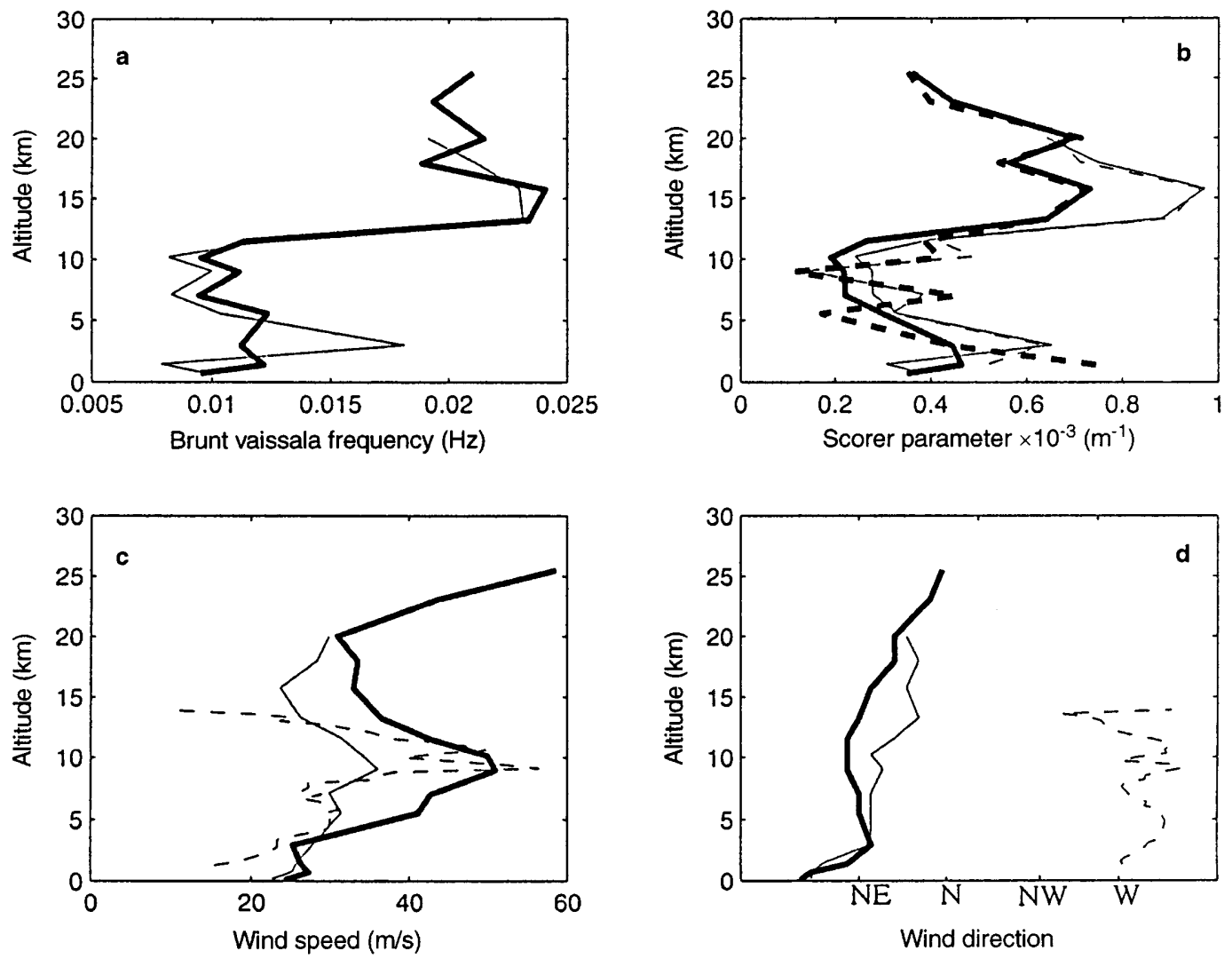

Fig. 12. Profiles for 26 January for 0 UT (thin line) and 12 UT (thick line) of a Brunt Vaissala frequency from radiosonde from Bodo. b Scorer parameter from radiosonde from Bodo (solid line: simplified, dashed: full expression, see text). c Wind intensity from radiosonde

from Bodo (solid), ESRAD radar data (24-h average - dashed) d Wind direction from radiosonde from Bodo (solid line), ESRAD radar data (dashed line) Zero degrees is westerly, +90 southerly

of wind at the tropopause. This is in line with (Prichard et al., 1995) who showed that the tropopause is often a critical layer with a change of the wind direction, a decrease of the mean wind and so an increase of $l$, and a decrease of critical horizontal wavelength. In fact, the appearance of enhanced radar reflectivity at the tropopause may be related to this since the absorption of gravity waves near a critical layer would lead to turbulence (Geller et al., 1975).

On the 26 of January (Fig. 12), the Brunt Vaissala frequency has a minimum in the upper troposphere. The profile on this day, would give elongation of the vertical wavelength and make wave activity increasingly vulnerable to reflection rather than continued propagation. The Scorer parameter decreases sharply between 4 and $6 \mathrm{~km}$ and remains low up to the tropopause at about $10 \mathrm{~km}$. This can be expected to lead to trapping under the tropopause, as observed (even strong wave activity in the lower troposphere was not seen in the vertical winds just above the tropopause). The wind speed increased from $1 \mathrm{~km}$ to $10 \mathrm{~km}$, where it decreased again but remained above $20 \mathrm{~m} / \mathrm{s}$. The wind direction changed little with height. So we expect no critical-layer effects.

As we have seen before, the 26 corresponds to a situation just before the passage of a cold front, so it is associated with a thermal circulation, leading to a decrease of $N$ with height, and so a decrease of the Scorer parameter.

As a final check, it is useful also to study how the frequency spectrum of gravity waves in our data varies with height. In a previous study, Ecklund et al. (1986) have shown that, during mountains wave events, the frequency spectrum of $\mathrm{W}$ has a power law behaviour with a power spectral density varying as $w^{-5 / 3}$, with $w$ the frequency, compared with a $w^{0}$ dependence during quiet days.

Because the frequency spectrum of $\mathrm{W}$ changes from $w^{-5 / 3}$ to $w^{0}$ over a height interval of just a few $\mathrm{km}$ from below to above a critical layer (or a trapping layer, Worthington and Thomas, 1996), we have plotted in Fig 13a-c spectra for the 10th, 24th and 26th, respectively. We show the power spectral density of W (vertical wind) in the lower part of the troposphere (1$3 \mathrm{~km}$ ) and in the upper levels above $8 \mathrm{~km}$ for the $10 \mathrm{th}$, above $10 \mathrm{~km}$ for the 26th and above $11 \mathrm{~km}$ for the 24th. The different upper levels have been choose as a function of the conditions for each day studied. First for the 10th, we choose $8 \mathrm{~km}$ because we have good data only until $10 \mathrm{~km}$, due to the presence of the trough. For the 26th, we have seen that the Scorer parameter is minimum at $10 \mathrm{~km}$, so the waves should be trapped 

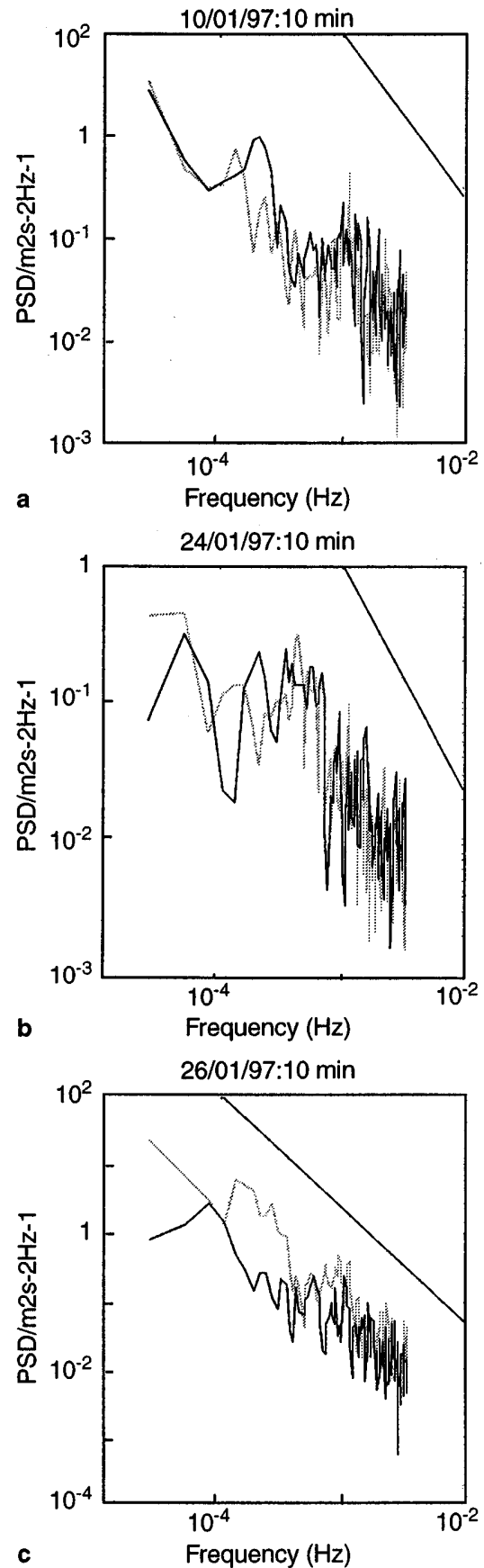

Fig. 13 a-c. For 10, 24 and 26 January, respectively: power spectral density of vertical wind fluctuations in the lower part of the troposphere (1-3 km) (black) and in the upper levels (gray) above $8 \mathrm{~km}$ for the 10th, above $10 \mathrm{~km}$ for the 26th and above $11 \mathrm{~km}$ for the 24th

Table 2. Temperature at 475 and 550 isentropics levels

\begin{tabular}{lllllll}
\hline & \multicolumn{3}{l}{ Isentropic level } & & & \\
\cline { 2 - 5 } Days & $475 \mathrm{~K}$ & & & $550 \mathrm{~K}$ & & \\
\cline { 2 - 3 } \cline { 5 - 6 } Time & $00: \mathrm{UT}$ & $12: \mathrm{UT}$ & & $00: \mathrm{UT}$ & $12: \mathrm{UT}$ & \\
\hline 10 & $205.7 \mathrm{~K}$ & 203.9 & & $197.2 \mathrm{~K}$ & 196.8 & PSCs \\
24 & $199.7 \mathrm{~K}$ & 201.7 & & $194.1 \mathrm{~K}$ & 195.0 & No PSC \\
26 & $206.1 \mathrm{~K}$ & 209.1 & & $197.9 \mathrm{~K}$ & 201.4 & No PSC \\
\hline
\end{tabular}

under this level. For the 24, the Scorer parameter is uncertain at lower heights, and the wind shear is at about $11 \mathrm{~km}$ which is the height of the tropopause.

On the 10th the two spectra are very similar with slightly more energy at the upper level at frequencies above $10^{-3}$ Hertz. We can see also a dependence of the form $w^{-5 / 3}$ in the same frequency interval showing the presence of the lee waves at both levels. On the 24th there is little difference in the energy at the two levels. This is perhaps because we are still in the critical layer at the upper level. Nevertheless, the peak of energy at $3.5 \times 10^{-4}$ Hertz at the lower levels is not seen in the upper levels. With a mean wind of around $15 \mathrm{~m} / \mathrm{s}$, this corresponds to a wavelength of $43 \mathrm{kms}$. On the 26th, we can see a strong decrease of the energy in the upper level at the lowest frequencies, consistent with the waves being trapped.

\section{Discussion}

\subsection{Influence of the waves on the formation of PSCs (including nacreous clouds)}

Polar stratospheric clouds are clouds located in the lower stratosphere, usually between 15 to $30 \mathrm{~km}$, which are formed under very low temperatures. PSCs can be observed by lidar or aircraft or even airborne lidar (Carslaw et al., 1998a, b). Nacreous clouds (Störmer, 1940) are one type of PSCs which are seen visually from the ground. They are seen often in the Kiruna area, usually in January/February but also at times in December and March. In the middle of the winter, when the sun is below the horizon all day, the sunlight scattered from the cloud particles gives spectacular, brightly coloured nacreous clouds which can easily be distinguished from ordinary, tropospheric clouds.

From models results (Hanson and Mauersberger, 1988), we know that the threshold temperatures for formation of PSCs (considered to be formed from NAT, Nitric acid trihydrate), according to the LIMS profile (Gille and Russel, 1984), is around $195 \mathrm{~K}$ at the $475 \mathrm{~K}$ isentrope (which corresponds to an altitude around $20 \mathrm{~km}$ ) and $192 \mathrm{~K}$ at $550 \mathrm{~K}$ (around $23 \mathrm{~km}$ ). We expect waves to be important for the formation of PSCs especially when the stratospheric temperatures would be too high for cloud formation in the absence of waves; The vertical propagation of the waves leads to localized adiabatic lifting of the atmosphere which then cools adiabatically making formation of PSCs more likely (Hesstvedt, 1958).

Temperature data from ECMWF (European Center For Medium Range Weather Forecast) for the $475 \mathrm{~K}$ and $550 \mathrm{~K}$ levels at 0:00 UT and 12:00 UT over the station $(67.9 \mathrm{~N}, 21.1 \mathrm{E})$ are shown in Table 2. For all the cases studied here the synoptic (ECMWF) temperature is not low enough for the formation of PSCs, so if there were PSCs present, they must be due to help from the waves causing localised adiabatic cooling in the stratosphere. 
The presence of PSCs can be monitored by lidar, when the weather and light conditions permit operations. The University of Bonn lidar operated at Esrange during the campaign. However, it did not operate continuously; On the 10th, it operated from 17:4224:00, on the 24th, from 10:17 h until 24:00, and on the 26th, from 14:20-23:05. No PSCs were detected on any of the three days. (K.-H. Fricke, priv.comm). However, on the 10th, the sky was clear the whole day and we observed nacreous clouds between 12-14 UT, during a period when the lidar was not operating. So it seems likely that the strong waves which we see in the radar data at this time, propagating up to the lower stratosphere, must have helped for the formation of stratospheric clouds. The temperature at $475 \mathrm{~K}$ was more than $10 \mathrm{~K}$ above the threshold of formation of PSCs, so the waves must have been indispensable to cool the atmosphere for the creation of PSCs.

On the 24th, we did not see any nacreous clouds or PSCs although the lidar observations covered most of the day. So the absence of clouds in the stratosphere is nearly certain. The temperatures on the 24 th were lower than on the 10th, so the absence of clouds is consistent with our observation that the waves did not propagateup to the stratosphere.

Even with the strong wave activity in the lower part of the troposphere on the 26th, no PSCs and no nacreous clouds were observed during this day either (although viewing conditions were poor before $14 \mathrm{UT}$ ). The temperatures at the beginning of this day were similar to those on the 10th. Moreover, the waves were strong even after 14:20 UT, when the lidar observations started. This again, is consistent with our radar observation: good vertical propagation on the 10th but not on the 24 th and the 26th.

\subsection{Conclusion}

In this study, we show three cases in January 1997 of mountain lee waves present in different conditions and with different upward propagation characteristics. The event on the 10th, was associated with the passage of a trough with strong surface winds from the NW and strong waves which propagated freely vertically as the atmospheric stability increased with the height.

On the 24th, the wind was from NE and a welldefined, high tropopause associated with an anticyclonic ridge seemed to represent a critical layer which prevented vertical propagation of the waves.

The third case (26 January 1997) was associated with winds from the $\mathrm{W}$ and strong waves at the surface which were trapped under the tropopause due to the influence of the thermal circulation before a cold front. This decreased the atmospheric stability at the upper heights. In all these cases the wind crossed the Scandinavian mountains but the wave vertical propagation depended heavily on the vertical profile of the horizontal winds and the conditions of stability (which are a function of the gradient of the temperature). These conditions are related to the synoptical conditions and suggest that further analysis of a larger database can lead to a worthwhile classification of the conditions for leewave propagation in terms of synoptic weather conditions. Finally, we show that propagation of waves to the stratosphere on 10 January 1997 was correlated with the production of polar stratospheric clouds. Our observed correlation between upward wave propagation and synoptic weather conditions may allow improved predictions of when and where these clouds can form.

Acknowledgements. We particularly want to acknowledge Dr. K-H Fricke for organizing the multi-instrument lee-wave campaign in 1997 and Dr. Karin Petzoldt for help in interpreting weather maps. The work of A.Réchou, V.Barabash, P.Chilson, T. Savitskaya and $\mathrm{K}$. Stebel is financed by the Environment and Space Research Institute in Kiruna (MRI), S. Kirkwood and part of ESRAD are financed by the Swedish Natural Science Research Council(NFR). ESRAD is otherwise financed by Swedish Space Corporation.

Topical Editor F. Vial thanks H. Volkert for his help in evaluating this paper.

\section{References}

Adams, N., The detection and analysis of a gravity wave observed over Casey in East Antarctica using radiosonde data, Australian Meteorol. Mag., 45, 219-232, 1996.

Attie, J. L., A. Druilhet, B. Benech, and P. Durand, Comptes-rendus scientifiques des experiences aeroportees realisees avec l'ARAT et le Merlin IV pendant PYREX. Laboratoire d'Aerologie, Toulouse, 1991.

Balsley, B. B., and D. A. Carter, Mountain waves in the tropical pacificatmosphere - a comparison of vertical wind fluctuations over Pohnpei and Christmas Island using VHF wind profilers, J. Atmos. Sci., 46, 2698-2715, 1989.

Blumen, W., and J. E. Hart, Airborne Doppler Lidar windfield measurements of waves in the lee of Mount Shasta, J. Atmos. Sci., 45, 1571-1583, 1988.

Bougeault P., A. Jansa, J. L. Attie, I. Beau, B. Benech, R. Benoit, P. Bessemoulin, J. L. Caccia, J. Campins, B. Carissimo, J. L. Champeaux, M. Crochet, A. Druilhet, P. Durand, A. Elkhafi, P. Flamant, A. Genoves, M. Georgelin, K. P. Hoinka, V. Klauss, E. Koffi, V. Kotoni, C. Mazaudier, J. Pelon, M. Petitdidier, Y. Pointin, D. Puech, E. Richard, T. Satomura, J. Stein, and D. Tannhauser, The atmospheric momentum budget over a major mountain range: first results of the PYREX field program, Ann. Geophys., 11, 385-418, 1993.

Bretherton, F. P., Momentum transport by gravity waves, $Q . J . R$. meteorol. Soc., 95, 213-243, 1969.

Carslaw, K. S., M. Wirth, A. Tsias, B. P. Luo, A. Dörnbrack, M. Leutbecher, H. Volkert, W. Renger, J. T. Bacmeister, E. Reimer, and Th. Peter, Increased stratospheric ozone depletion due to mountain-induced atmospheric waves, Nature, 391, 675-678, 1998a.

Carslaw, K. S., M. Wirth, A. Tsias, B. P. Luo, A. Dörnbrack, M. Leutbecher, H. Volkert, W. Renger, J. T. Bacmeister, and Th. Peter, Particle microphysics and chemistry in remotely observed mountain polar stratospheric clouds, J. Geophys. Res., 103, 5785-5796, 1998b.

Clarke, T. L., T. Hauf, and J. P. Kuetter, Convectively forced internal gravity waves: Results from two-dimensional numerical experiments, Q. J. R. Meteorol. Soc., 112, 899-925, 1986.

Conover, J. H., The identification and the significance of orographically induced clouds observed by TIROS satellites, J. Appl. Meteorol., 3, 226-234, 1964.

Corby, G. A. and J. S. Sawyer, The airflow over a ridge: The effect of the upper boundary condition and high-level conditions. Q. J. R. Meteorol. Soc., 84, 25-37, 1958. 
Dörnbrack, A., M. Leutbecher, H.Volkert, and M. Wirth, Mesoscale forecasts of stratospheric mountain waves. Meteorol. Appl. 5, 117-126, 1998.

Ecklund, W. L., K. S. Gage, and A. C. Riddle, Gravity wave activity in vertical winds observed by the Poker Flat MST radar, Geophys. Res. Lettl., 8, 285-288, 1981.

Ecklund, W. L., K. S. Gage, B. B. Basley, R. G. Strauch, and J. L. Green, Vertical wind variability observed by VHF radar in the lee of the Colorado Rockies, Mon. Weather Rev., 110, 14511457, 1982.

Ecklund W. L., K. S. Gage, G. D. Nastrom and B. B. Balsley, A preliminary climatology of the spectrum of vertical velocity observed by clear-air Doppler radar, Journal of Climate and Applied Meteorology, 25, 1986.

Fovell, R., D. Durran, and J. R. Holton, Numerical simulations of convectively generated stratospheric gravity waves, J. Atmos. Sci., 49, 1427-1442, 1992.

Fricke, K. H., K. P. Müller, M. Serwazi, J. Reichardt, S. Kirkwood, A Steen, P. Hoffmann, H. Mehrtens, A. Hauchecorne, F. Fierli, U. P. Hoppe, and G. Hansen, report name: Air pollution report 66, Polar stratospheric ozone 1997 Wind generated polar stratospheric clouds: The case of January 16, 1997 in Northern Scandinavia, Polar stratospheric ozone 1997, Air pollution research report 66, European Commission, 127-130, 1998.

Gage, K. S., and J. L. Green, Tropopause detection by partial specular reflection using VHF radar, Science, 203, 1238-1240, 1979.

Geller, M. A., H. Tananaka, and D. C. Fritts, Production of turbulence in the vicinity of critical layers for internal gravity waves, J. Atmos. Sci., 32, 2125-2135, 1975.

Gille, J. C. and J. M. Russel, The limb infrared monitor of the stratosphere: Experiment description, performance, and results, J. Geophys. Res., 89, (D4), 5125-5140, 1984.

Griffiths, M., and M. J. Reeder, Stratospheric inertia-gravity waves generated in a numerical model of frontogenesis. I: Model Solutions, Q. J. R. Meteorol. Soc., 122, 1153-1174, 1996.

Hanson, D. and K. Mauersberger, Laboratory studies of the nitric acid trihydrate: Implication for the south polar stratosphere, GRL, 15, 855-858, 1988.

Hesstvedt, E., Mother of pearl clouds in Norway. Geophysica Norvegica, 10, 1-29, 1958.

Holton, J. R., An introduction to dynamic meteorology, 3rd. edn., Academic Press, London, 1992.

Larsen, M. F., and J. Röttger, VHF and UHF Doppler radars as tools for synoptic research, Bull. Am. Meteorol. Soc., 63, 9961008, 1982.
Leutbecher, M., and H. Volkert, Stratospheric temperature anomalies and mountain waves: A three-dimensional simulation using a multi-scale weather prediction model, Geophys. Res. Lett., 23, 3329-3332, 1996.

Lilly, D. K., R. M. Chervin, P. J. Kennedy, and J. B. Klemp, Aircraft measurements of wave momentum flux over the Colorado Rocky Mountains, Quart. J. Roy. Meteor. Soc., 108, 625-642, 1982.

Lott, F., and H. Teitelbaum., Topographic waves generated by a transient wind, J. Atmos. Sci., 50, 2607-2624, 1993.

Müller, K. P., G. Baumgarten, J. Siebert, K. H. Fricke, PSCs Observations with the new lidar facility at Esrange, Kiruna in winter 1996/1997, Polar stratospheric ozone 1997, Air pollution research report 66, European Commission, 155-158, 1998.

Nastrom, G. D., D. C. Fritts, and K. S. Gage, An investigation of terrain effects on the mesoscale spectrum of atmospheric motions, J. Atmos. Sci., 44, 3087-3096, 1987.

Nastrom, G. D., and D. C. Fritts, Sources of mesoscale variability of gravity waves. Part I: Topographic excitation, J. Atmos. Sci., 49, 101-110, 1992.

Prichard, I. T., L. Thomas, R. M. Worthington, The characteristics of mountain waves observed by radar near the west coast of Wales, Ann. Geophy., 13, 757-767, 1995.

Ralph, F. M., M. Crochet, and S. V. Venkateswaran, A study of mountain lee waves using clear-air radar, $Q . J . R$. Meteorol. Soc., 118, 597-627, 1992.

Réchou, A., V. Barabash, P. Chilson, S. Kirkwood, T. Savitskaya, and K. Stebel, ESRAD MST radar analysis of waves, Polar stratospheric ozone 1997, Air pollution research report 66, European Commission, 70-73, 1998.

Scorer, R. S., Theory of waves in the lee of mountains, Quart J. Roy. Meteor. Soc., 75, 1949.

Serwazi, M., J. Reichardt, A. Behrendt, R. Baumgart, C. Weitkamp and B. Neidhart, First measurements of ozone profiles in the presence of polar stratospheric clouds with a Raman differential absorption lidar at Esrange/Kiruna in January 1997, Polar stratospheric ozone 1997, Air pollution research report 66, European Commission, 224-227, 1998.

Störmer, C., Observations and photographic measurements of mother of pearl clouds over Scandinavia, 1930-1938, part 2, Geofys. Publ., 12, 1940.

Worthington, R. M., and L. Thomas, Radar measurements of a critical-layer absorption waves, Q. J. R. Meteorol. Soc., 122, 000-020, 1996. 